\title{
ESTUDO INTERINSTITUCIONAL DA REGIÃO CENTRO OESTE: AS PRODUÇÕES DO PROGRAMA DE MESTRADO EM EDUCAÇÃO DA UNIUBE
}

\author{
Sueli Teresinha de Abreu-Bernardes ${ }^{1}$ \\ Maria Aura Marques Aidar ${ }^{2}$ \\ Giselle Naves de Oliveira Costa ${ }^{3}$ \\ Sandra Mara Dantas ${ }^{4}$ \\ Janete Aparecida Pereira-Melo ${ }^{5}$
}

Projetos e Práticas de Formação de Professores

\section{Partilha, pesquisa}

A compreensão do sentido do todo, para o qual convergem as várias dimensões da existência; o intercâmbio entre campos e domínios das diferentes ciências; o vínculo entre tipos de conhecimento e vocações do saber parecem estar esvaecendo. No entanto, refletimos com Brandão (2005, p. 103-104), "somente uma nova compreensão, ao mesmo tempo capaz de abarcar 0 absoluto da individualidade e da diferença, e a criação contínua e diferenciada de totalidades, poderá voltar-se à complexidade da Vida e do Mundo no presente momento, aqui e agora". Pensamos em uma pesquisa solidária, partilhada, coletiva, em que os pesquisadores de vários estágios de formação, experiência e sabedoria interagem para criar conhecimento.

Com esse pensamento, fundamentamos nossa atitude investigativa no trabalho relatado neste texto. Queremos apresentar aqui o estágio atual de uma pesquisa interinstitucional em andamento na região Centro-Oeste, no período de 1999 a 2005. Desse estudo participam programas de pós-graduação stricto sensu em educação de universidades da referida região: UFG, UnB, UFMS, UFMT, UFT, UFU e UNIUBE.

\footnotetext{
${ }^{1}$ UNIUBE gui2009@terra.com.br

2 UNIUBE maria.aidar@yahoo.com.br

${ }^{3}$ PIBIC/UNIUBE giselle_naves@hotmail.br

4 UFTM sandra.dantas@netsite.com

${ }^{5}$ UNIUBE pereira.janete@gmail.com

Agência de financiamento: FAPEMIG
} 
O objeto em estudo é a produção acadêmica que tem como foco o professor. Da especificidade de cada trabalho e de cada programa, buscamos uma compreensão das tendências, dos enfoques metodológicos, dos referencias e das concepções que permeiam as produções regionais. Há uma totalidade a ser identificada e a troca de experiência de leituras das várias equipes de pesquisadores tem permitido uma interação e uma inter-relação de conhecimentos sobre o que é produzido sob a moldura do cerrado goiano, mato-grossense e mineiro.

A investigação tem ainda como proposta contribuir para subsidiar estudos e pesquisas sobre o tema fornecendo dados sobre este trabalho para os orientadores dos respectivos programas; detectar lacunas e criar espaços interativos que promovam o debate entre os pesquisadores da área e, posteriormente, 0 aprimoramento de suas produções acadêmicas.

Dentre os diálogos que estamos realizando, citamos as reflexões de, entre outros, Duarte (2000) e Costa (2002). O primeiro, critica a ausência da perspectiva da totalidade nas pesquisas em educação que se limitam ao micro, ao caso isolado, ao particular. Ele chama a atenção para a fragilidade das pesquisas em educação que adotam a metodologia qualitativa que "com raras exceções, pouco ou nada acrescentam ao processo de compreensão do concreto enquanto uma rica totalidade com múltiplas determinações e relações diversas".

Costa (2002), em seus trabalhos tem salientado a concepção segundo a qual o discurso, as narrativas, os textos científicos, têm um papel constitutivo e assim, não apenas descrevem as coisas, os fatos, mas instituem as coisas, inventando e produzindo sua existência. E, como os discursos também operam na constituição dos sujeitos, torna-se importante desvelar como se tem escrito sobre os sujeitos, os grupos, os professores e as professoras. Citando Popkewitz (1997), para quem as idéias "podem ser vistas como sistemas que demarcam e moldam como deve ver-se o mundo, que possibilidades estão disponíveis e são razoáveis", ressalta a importância de investigar como os discursos sobre os docentes estão produzindo os próprios docentes, como tais discursos instigam os docentes a serem da forma como são.

As pesquisas realizadas por André (1999), Cunha (1998) e Loureiro (2003) também têm sido importantes nas discussões dos primeiros resultados, pois apontam caminhos e nos alertam para possíveis embaraços no processo investigativo. 
Pensando a pesquisa como uma construção colaborativa e interativa de aprendizagem seu desenvolvimento ocorre em um grupo que se divide e se integra em estudos e trabalhos. Entendemos que a construção do conhecimento

[...] não é fragmentado, mas interdependente, interligado, intersensorial. Conhecer significa compreender todas as dimensões da realidade, captar e expressar essa totalidade de forma cada vez mais ampla e integral. Conhecemos mais e melhor conectando, juntando, relacionando, acessando o nosso objeto de todos os pontos de vista, por todos os caminhos, integrando-os da forma mais rica possível. (MORAN, 2001, p. 18)

E na tessitura de uma rede de pesquisadores percebemos as possibilidades de análise das concepções, temas e procedimentos metodológicos das pesquisas sobre o professor no curso de Mestrado da Universidade de Uberaba.

Após o convite da coordenação geral da pesquisa à equipe de professores da UNIUBE, em 2007, para o desenvolvimento do referido subprojeto, a equipe inicial de pesquisadores foi composta por cinco professoras dos cursos de licenciatura, dois professores e dois alunos do Mestrado em Educação e uma técnicaadministrativa da instituição. Atualmente, essa equipe conta com a participação de duas professoras doutoras, duas mestres, duas especialistas e uma aluna de iniciação científica. Procuramos, assim, a formação de um grupo que na dimensão horizontal e vertical, abrangesse alunos e professores de vários níveis de formação.

Ao longo dos dois últimos anos, a equipe realiza estudos em uma perspectiva colaborativa em que revisitamos, sob a diversidade de olhares dos pesquisadores, 0 referencial teórico proposto e garantimos a coesão do grupo. Pois, conforme nos diz Foucault (1998, p. 13) "existem momentos na vida em que a questão de saber se é possível pensar diferentemente do que se pensa, e perceber diferentemente do que se vê é indispensável para continuar a olhar ou a refletir".

A equipe analisa as dissertações dos egressos do Programa de Mestrado em Educação da UNIUBE, defendidas no período de 2003 a 2005, com o objetivo de identificar a presença maior ou menor dos diferentes temas, referenciais teóricos, metodológicos, conceituais da educação, do professor, do processo de ensinoaprendizagem, detectar lacunas, apontando temas e referenciais teóricos ausentes ou insuficientemente explorados, contribuindo assim para subsidiar estudos e pesquisas sobre o docente.

Nesse contexto, o Programa tem um significado muito especial, uma vez que desenvolve uma linha específica voltada para a área de formação de professores 
que atuam em diferentes campos, níveis e modalidades de ensino. Suas linhas de pesquisas concentram-se em: 1) Formação de Professores e Processos Educativos e 2) Cultura, Educação e Sociedade. Essa especificidade da proposta possibilita aos educadores a aproximação entre a teoria e suas práticas no cotidiano escolar, interagindo em sua realidade e superando desafios para transformá-la.

Para este trabalho, fazemos um recorte dessas produções enfocando a análise de vinte por centro das dissertações produzidas.

\section{Percurso, indagação}

Considerando o professor não como o único, mas como um agente significativo da prática pedagógica parece-nos relevante e oportuno encontrar respostas a questões como: "É possível visualizar uma tendência de concepção de formação de professores, profissionalização, prática docente, educação e professor na produção dos discentes do nosso programa? Como a produção acadêmica do curso de Mestrado em Educação da Universidade de Uberaba a reflete?"

O grupo local da pesquisa realizou, como procedimento inicial, a leitura das dissertações e o preenchimento da ficha de análise onde estão categorizadas as informações pertinentes ao projeto. Nesta ficha, além de dados de identificação do trabalho, constam itens que apresentam os temas estudados, o referencial teórico, os procedimentos do autor em relação ao método, o tipo de pesquisa, a concepção de educação e de professor e, também, outros aspectos relevantes.

Os primeiros encontros do grupo foram de muita discussão e reflexão sobre o referencial teórico, a compreensão dos conceitos relativos aos procedimentos de pesquisa, a forma de desenvolvimento da leitura das dissertações e do preenchimento da ficha de análise. Procurou-se construir uma unidade conceitual do grupo em relação aos itens requeridos na ficha.

Desse modo, as leituras iniciais foram intercaladas por reflexões, já que se tornava necessário identificar e diferenciar elementos essenciais à análise das produções científicas. Não raro, surgiam dúvidas, tais como: o que estamos entendendo por método e por metodologia? Como o pesquisador teceu sua interpretação do referencial teórico anunciado? Como caracterizar a pesquisa-ação e a pesquisa participante? Com o passar do tempo, foram delineados os aspectos centrais do estudo e desenvolvida a análise de cada produção, com profundidade. A 
riqueza da pesquisa está na ampliação dos conhecimentos que esta propicia à equipe.

O levantamento das produções defendidas e a identificação de suas linhas de pesquisa foram realizados concomitantemente ao estudo e a reflexão sobre o referencial teórico da pesquisa e sua fundamentação metodológica.

Durante o trabalho da pesquisa, já foram realizados dez seminários regionais para socialização dos resultados parciais das análises realizadas em cada universidade participante do projeto interinstitucional. Vale ressaltar que, nesses encontros, a dialogicidade e a interação entre os pares tornaram-se intensas, na diversidade de temas que demandavam aprofundamento das referências e, sobretudo, quanto à aprendizagem sobre a forma de se fazer essa pesquisa em rede.

Esses momentos de partilha eram relatados, pelo membro da equipe local que participava, e intensamente refletidos, pois se tornavam um manancial de experiências. Dessa forma o grupo considera que a riqueza da pesquisa está na ampliação dos conhecimentos que esta propicia à equipe. Uma vez que entendemos que $\mathrm{o}$ ato investigativo como um ato de criação, abrange o imaginário, a afetividade, a emoção, aliados ao entendimento e à reflexão do real (ABREU-BERNARDES, 2008, p. 35). O senso comum relaciona a criatividade e a sensibilidade apenas ao artista. Entendemos, porém, que em todo fazer humano elas estão presentes. Esses dizeres são atentos ao que escreve a artista plástica Fayga Ostrower: "inata, ou até mesmo inerente à constituição do homem, a sensibilidade não é peculiar somente a artistas ou alguns poucos privilegiados" (1987, p. 12).

\section{Professor, estudo}

As primeiras construções indicam que os pesquisadores do programa optam por fazer estudos que explicitam, analisam e problematizam situações do cotidiano da prática docente tendo em vista a formação do professor.

Em uma das investigações, a pesquisadora.' destaca que a formação dos professores desafia a prática docente, pois nem sempre a cotidianidade da sala de aula reflete o discurso teórico do professor: 
repetindo conceitos piagetianos, sem saber aplicá-los, sem preocupar com o significado de "pescar o humano no homem" e a proposta com base na pedagogia histórico-crítica pela Secretaria Municipal de Educação, Gestão 93/96

Ainda com relação ao cotidiano escolar e a formação de professores, outra autora, que discorre sobre o tema inclusão, aponta:

Com referência à "Educação para Todos" pretende-se ressaltar a necessidade da formação de professores para que, munidos de conhecimentos, tenham eles condições de conviver com os alunos que apresentam diferenças e atuar, seguindo um dos princípios da inclusão, o de que todos os alunos devem aprender juntos, mesmo que apresentem diferenças.

Muitos trabalhos indicam a importância da formação continuada, como destacado na citação em que o pesquisador relata a necessidade dessa formação para que o professor possa participar da construção e transformação do currículo.

A formação continuada de profissionais contribui para abrir novos horizontes, no referente à fundamentação teórico-pedagógico que fortalecerá essa preparação, para que, como profissionais qualificados, possam atender tais alunos, através da capacidade para incrementar um currículo voltado para essa parcela da população.

Percebemos, também, algumas dissertações voltadas para o uso das tecnologias de informação e comunicação, evidenciando a preocupação com um campo de estudo emergente e em constituição, conforme observamos abaixo, no recorte de um trabalho analisado:

O estudo que desenvolvemos justifica-se pela importância que vem ganhando o uso dos computadores e mais especificamente a Internet na educação, quer seja em relação à educação à distância, o intercâmbio de experiência de aprendizagem, ou à pesquisa do aluno, visando melhorias que se fazem necessárias quanto ao ensinar, ao aprender e às novas formas de conceber a relação entre professor, aluno e objetos de conhecimento.

E, do mesmo modo, o cuidado com as estratégias para promoção da interatividade nos ambientes:

[...] outra função educativa do computador é a possibilidade da intercomunicação, com a qual, em um mesmo ambiente, vários computadores estão interligados em rede, favorecendo a interação dos alunos entre si por meio do envio e do recebimento de mensagens.

Os textos acima destacados ilustram que a prática docente permeia as pesquisas já analisadas e que denotam uma preocupação com a introdução das tecnologias na educação e as práticas pedagógicas a elas relacionadas. 
À luz de teorias sobre o profissional reflexivo, de modo predominante, esses pesquisadores buscam entender como os estudos teóricos e a prática docente se inter-relacionam, conforme explicitado abaixo:

A prática deve ser objeto de sua reflexão com a finalidade de, teoricamente embasada, produzir uma práxis criadora, ou seja, criar uma nova teoria a partir de sua prática refletida.

Observamos, igualmente, que várias dissertações destacam a necessidade da unidade teoria e prática, evidenciadas nas duas citações que se seguem:

Num processo mecânico de ensino, a teoria se encontra dissociada da prática e isso gera um tolhimento, dificulta o processo do conhecimento. Para a construção do conhecimento, precisamos perceber a teoria e a prática como sendo dois lados de um mesmo objeto. Teoria e prática somente se realizam como práxis, ao se agir conscientemente de sua simultaneidade e separação dialética.

Identificamos a predominância da tendência crítica tanto no que tange à formação de professores quanto às concepções de educação e de professor. Em dissertações analisadas encontramos reflexões sobre a articulação do processo educativo ao contexto sócio-histórico que o gera; sobre a compreensão da educação como transformadora da realidade social, como encontramos nas citações a seguir, extraídas de três dissertações:

É imprescindível que se estabeleça uma educação realmente comprometida com o ser humano, vinculada à realidade, pautada por uma organização e estruturação de idéias para onde possam convergir interesses sociais não dominadores, interesses políticos e filosóficos do ser humano, capazes de propiciar um desenvolvimento global da sociedade. Para isso, a educação deve necessariamente, resultar de uma prática pedagógica em constante renovação.

A educação é um processo ativo, por isso se apóia e se realiza em bens culturais vividos.

[...] formação continuada, concebida [...] através de um trabalho de reflexão crítica sobre as práticas e de (re) construção permanente de uma identidade pessoal e profissional em interação mútua, comprometida com a realidade de seu tempo e com um projeto de sociedade justa e democrática.

Aspectos de outras tendências igualmente estão presentes no conjunto das dissertações analisadas, como a consideração da complexidade, da provisoriedade e da incerteza, características da tendência pós-crítica:

A ação educativa é eminentemente humana e sempre que indagamos diferentes pessoas acerca de quais experiências mais marcaram sua vivência escolar são aquelas lembranças carregadas de afeto, histórias venturosas e momentos impregnados de significado e expressão. 
Estes professores vivem a ambigüidade e a complexidade do tempo científico presente, no qual coexistem, na mesma instituição, e até no mesmo professor, enfoques antagônicos de conceituação de ciência e ensino, derivados de posições epistemológicas também diferentes, provocadas pela própria formação de origem.

Com relação ao método utilizado nas produções, verificamos que os pesquisadores não o explicitaram com clareza. Observamos que não há um purismo metodológico ao se identificar, por exemplo, as características do método materialista histórico-dialético e do fenomenológico. Nessa amostra de trabalhos analisados, o caminho percorrido para realizar a pesquisa é evidenciado, sendo predominante a abordagem qualitativa. Algumas vezes o método é inferido da leitura do referencial teórico e também do tipo de pesquisa realizado.

Os trabalhos desenvolvidos apontam uma coerência entre o tipo de pesquisa e a tendência crítica predominante nas produções. Na amostra analisada há a ocorrência de estudos de caso, pesquisa-ação, pesquisa participante e pesquisa histórica como denotativo do propósito dos autores em intervir na realidade. Isso é evidenciado na citação abaixo em que o pesquisador opta por uma pesquisa-ação:

Dentre as várias formas que pode assumir uma pesquisa qualitativa, optamos pela pesquisa-ação, em função de melhor se enquadrar no tipo de problema levantado para este estudo: a pesquisa ação tem o objetivo de ajudar a resolver ou, pelo menos, esclarecer os problemas da situação observada, por meio de um acompanhamento das decisões, das ações, e de toda a atividade intencional dos sujeitos da situação.

A pesquisa histórica é desenvolvida em outros trabalhos, alguns utilizando a metodologia da história oral, como visto no fragmento abaixo:

[...] as entrevistas enfocam o relato da história de formação e profissão dos docentes, por meio da técnica da história oral temática. Essa prática é motivada e dirigida pelo conhecimento e pela ciência, havendo motivos e formas para realizá-la. A entrevista que está fundamentando esta pesquisa caracteriza-se pela construção das histórias das professoras, através de suas respostas, as quais venham atender a realidade do tema em questão, produzindo um discurso racionalizado do entrevistado.

Estudos de caso também foram desenvolvidos em outras pesquisas com destaque para o item da ficha de aprofundamento que contempla fontes de informações variadas, dados coletados em diferentes momentos, em situações diversificadas e com uma pluralidade de informantes:

Analisamos dados de dois questionários, sendo o primeiro realizado no momento da entrevista com os pais e candidatos ao CIEM. O segundo consta de uma série de perguntas ordenadas, abrangendo as formas aberta, fechada e de múltipla escolha, respondido por professores e alunos. [...]. Entrevista semi-estruturada foi realizada com a finalidade de 
complementar um questionário aplicado anteriormente. A pergunta foi previamente estabelecida, registrada através da escrita, possibilitando o esclarecimento e aprofundamento de informações obtidas no questionário. [...] Análise documental: levando em consideração que essa pesquisa foi desenvolvida a partir da experiência vivenciada pelo próprio pesquisador e, portanto, sujeito a influencias subjetivas pelos componentes.

Foram feitas entrevistas e observações em situações de sala de aula e fora dela, nas reuniões informais do grupo bem como nas reuniões pedagógicas. [...] A coleta de dados se deu a partir de oficinas, onde cada instrutor teve a oportunidade de manifestar sua auto percepção, considerando também seus sonhos, expectativas e frustrações profissionais. [...]. Os dados coletados ao longo da pesquisa apontaram as carências apresentadas pelos instrutores e estas carências subsidiaram a elaboração do programa (P.D.P.). Foi considerada carência tudo o que os instrutores apontavam como algo que dificultava ou faltava para 0 desenvolvimento de seu trabalho. [...] Outra forma de levantamento de dados se deu por meio de conversas programadas ou informais com os instrutores. [...] A análise do planejamento de atividades para o semestre como roteiros de trabalho, também foram utilizadas como fonte de coleta de dados.

O coletivo foi contemplado em uma das pesquisas analisadas pelo envolvimento dos sujeitos do grupo, no sentido de transformá-lo, resolver problemas e buscar sua autonomia como é característico da pesquisa participante:

\begin{abstract}
Esta pesquisa transcorreu no dia-a-dia, no cotidiano da equipe de Design Pedagógico, do Programa de Educação a Distância e, portanto, os questionamentos, à exemplo do cotidiano, também sofreram transformações ao longo do processo. (...) Pesquisar em um processo coletivo de professores significou desenvolver competências para resolver problemas em grupo e autonomia em relação à busca e ao fazer por si mesmo. Por meio de uma rede de colaboração, na qual cada um ajuda o outro a se desenvolver, cada designer buscou desenvolver-se individualmente também. A colaboração implicou em postura de flexibilidade; abertura ao diálogo; busca de compreensão e articulação dos diferentes pontos de vista; vivência solidária e interdependência de idéias, crenças e valores.
\end{abstract}

Os referenciais teóricos recorrentes são escritores contemporâneos como Vera Candau (1995), Moacir Gadotti, José Contreras (2002), Foucault (1998), Jussara Hoffmann (2000), Maurice Tardiff (2003), Vygotsky (1988), Antonio Nóvoa (1997), e Phillipe Perrenoud (1999). Os procedimentos metodológicos fundamentamse, sobretudo, em autores como Marli André (2005), Menga Lüdke, Marisa Vorraber Costa (2002), Michel Thiollent (2007), Carlos Rodrigues Brandão (2003) e Gaudêncio Frigotto (1991).

Identificamos que o campo de pesquisa preferencial é a escola de educação básica, de onde também predomina a origem dos autores. Essa pode ser uma explicação, a ser verificada em etapas posteriores, pela opção de pesquisar o cotidiano escolar. É de seu círculo de cultura escolar que os pesquisadores 
escrevem.

\section{Trajetória, momento atual}

Os dados apresentados e ainda não discutidos apontam para uma coerência da proposta dos pesquisadores que, partindo de sua realidade, seus problemas e contradições, investigam questões relacionadas à prática docente, à formação de professores com vistas à intervenção e mudança da realidade vivida por eles. Daí a sua opção pela tendência crítica.

De tudo o realizado até agora, emerge a satisfação pelo trabalho em grupo com integrantes de realidades acadêmicas diversas, mas que já confirmam a validade das interações de conhecimento, de experiência, de buscas e de afeto. Dessa forma, a equipe de pesquisadores constitui uma rede de criadores e recriadores de sua trajetória e de sua busca. Transformando o caminho e realizando re-leituras de sua trajetória e de seus resultados.

Estamos sempre diante de um outro e nos construímos como uma pessoa mais e mais complexa e mais completa, na medida em que estamos permanentemente incorporando saber e re-equilibrando a nossa própria vida interior por meio de um trabalho de aprender em que eu descubro e me descubro no espelho do outro, no trabalho com o outro. Eis o mistério.

\section{Referências}

ABREU-BERNARDES, S.T.. A Poética na formação humana - leituras de uma educadora. 2008. 230 f. Tese (Doutorado em Educação) - Faculdade de Educação, Universidade Federal de Goiás. Goiânia, 2008.

ANDRÉ, Marli et alli. Estado da arte da formação de professores no Brasil. In: Educação \& Sociedade, ano XX, nº 68/especial. Campinas/SP: CEDES, dez, 1999.

ANDRÉ, Marli Eliza Dalmazo A. de. Estudo de caso em pesquisa e avaliação educacional. Brasília: Líber Livro, 2005.

BRANDÃO, Carlos. R. A canção das sete cores: educando para a paz. São Paulo: Contexto, 2005.

A Pergunta a várias mãos: a experiência da pesquisa no trabalho do educador. São Paulo: Cortez, 2003. (Série Saber com o outro; v.1).

CANDAU. V. M. (Org.). Rumo a uma nova didática. 7.ed. Petrópolis: Vozes, 1995. 
COSTA, Marisa V. (Org) Caminhos investigativos I: novos olhares na pesquisa em educação.2. ed. Rio de Janeiro: DP\&A,2002.

CONTRERAS, José. A autonomia de professores. São Paulo: Cortez, 2002.

CUNHA, Maria Isabel da. O professor universitário na transição de paradigmas. Araraquara: JM Editora, 1998.

DUARTE, N. Vygotski e o "aprender a aprender": crítica às apropriações neoliberais e pós-modernas da teoria vygotskiana. Campinas, SP: Autores Associados, 2000.

FOUCAULT, Michel. História da sexualidade. Rio de Janeiro: Graal, 1998. v. 2.

FRIGOTTO, Gaudêncio. O Enfoque da dialética materialista histórica na pesquisa educacional. In: FAZENDA, Ivani (Org.). Metodologia da pesquisa educacional. São Paulo: Cortez, 1991.

HOFFMANN, J. Avaliação mediadora. 17. ed. Porto Alegre: Mediação, 2000.

LOUREIRO, Marcio C. S. et alii. O professor na região centro-oeste: o estado do conhecimento. In: ENCONTRO DE PESQUISA EM EDUCAÇÃO DO CENTROOESTE-EPECO, 6, 2003. Anais... Campo Grande, EPECO, 2003.

MORAN, José Manuel. Ensino-aprendizagem inovadores com tecnologias audiovisuais e telemática. In: MORAN, José Manuel, MASETTO, Marcos e BEHRENS, Marilda. Novas tecnologias e mediação pedagógica. Campinas, SP: Papirus, 2000.

NÓVOA, Antonio (Org.). Os Professores e sua formação. Lisboa: Publicações Dom Quixote, 1997.

OSTROWER, Fayga. Criatividade e processos de criação. 12. ed. Petrópolis: Vozes, 1987.

PERRENOUD, P. Avaliação: da excelência à regulação das aprendizagens: entre duas lógicas. Porto Alegre: ARTMED, 1999.

POPKEWITZ, Thomas S. Reforma Educacional: uma política sociológica; poder e conhecimento em educação. Trad. Beatriz Afonso Neves. Porto Alegre:Artes Médicas, 1997.

SAVIANI, Dermeval. Pedagogia histórico-crítica: primeiras aproximações, 8. ed. revista e ampliada. Campinas: Autores Associados, 2003.

TARDIF, MAURICE. Saberes docentes e formação profissional. Petrópolis: Vozes, 2003.

THIOLLENT, Michel. Metodologia de pesquisa-ação. 15a. ed. São Paulo: Cortez, 2007.

VYGOTSKY, Leontiev. Linguagem, desenvolvimento e aprendizagem. SP, Icone, 1988. 
Notas

' Pelo caráter provisório dos dados desta pesquisa, optamos pela não identificação, neste momento, dos autores das produções lidas.

Recebido para publicação em: 20/12/2009

Aceito: 02/07/2010 